UDC: $316.775: 179.9 \quad$ https://doi.org/10.22190/JTESAP2102149B

Review research paper

\title{
INSTITUTIONAL STRATEGIES TO INCREASE EMI QUANTITY AND QUALITY IN RUSSIAN HIGHER EDUCATION INSTITUTIONS: COMPARATIVE ANALYSIS
}

\author{
Elena Belyaeva, Michael Freese \\ St Petersburg State University (SPSU), Faculty of Liberal Arts and Sciences, Russia
}

\begin{abstract}
The article starts by examining the reasons behind the relatively recent growth of English as a medium of instruction (EMI) in Russian higher education institutions, from internationalization to more altruistic motives. While internationalization in Russia has recently been facilitated through a top-down approach at a national level, the quantity and quality of courses and programs taught in English are the responsibility of Russian universities and are primarily managed at an institutional level. Russian higher education institutions (HEIs) have been employing several strategies such as international recruiting, long-term university partnerships and faculty development. The authors take a closer look at each strategy, assessing its strengths and weaknesses, and illustrating it with some examples. Comparative analysis of the strategies under scrutiny allows to highlight more effective ones which are likely to positively impact the quantity and quality of EMI in Russian higher education in the years to come.
\end{abstract}

Key words: English as a Medium of Instruction (EMI), faculty development, internationalization Russian higher education, institutional strategies, quality management

\section{DRIVING FORCES BEHIND EMI GROWTH IN RUSSIA}

One of the recent systematic reviews of English as a Medium of Instruction (EMI) in higher education (HE) that assessed the range and quality of research into EMI across all education stages, regions and countries (Macaro et al. 2018) indicates that EMI has been widely researched for the past two decades, whereas in Russian HE EMI has not yet been investigated on a large scale. Thus, the following discussion cannot claim to be research driven, but offers an overview of the current local practice.

Professional discourse on English used in HE across the globe has been using several acronymic terms such as English for Academic Purposes (EAP), English for Specific Purposes (ESP), Content and Language Learning (CLIL), Integrated Language and Content in Higher Education (ILCHE) and English as a Medium of Instruction (EMI). SchmidtUnterberger in her recent article (Schmidt-Unterberger, 2018) proposed the 'Englishmedium Paradigm,' or a framework for all the instructional types found in HE. Using the suggested paradigm as a reference point, it may be argued that in Russian Higher Education

Submitted January $13^{\text {th }}, 2021$, accepted for publication March $4^{\text {th }}, 2021$

Corresponding author: St Petersburg University (SPSU), Faculty of Liberal Arts and Sciences, 58-60 Galernaya

Street, St. Petersburg, 190000, Russia|E-mail: lena.belyaeva@gmail.com

(C) 2021 by University of Niš, Serbia | Creative Commons License: CC BY-NC-ND 
Institutions (HEIs) EAP and ESP belong to the domain of English language as a subject in the HE curriculum. CLIL, more characteristic of a secondary sector, and ILCHE, potentially relevant for the tertiary sector, require the involvement of language specialists in syllabus design, course delivery and team teaching (Gustafsson \& Jacobs, 2013), which would require resources beyond most Russian HEIs' budgets. Due to the financial burden, ILCHE is currently non-existent in Russia. We, therefore, argue that English as a Medium of Instruction is being currently implemented in Russian HEIs and has the potential to become the dominant term to embrace most of the English-taught courses and degree programs. In this paper, EMI will refer to the teaching of a university subject or discipline through the medium of the English language where English is not the national language (Dearden, 2015).

In Russian HE the rise of EMI is apparent and is generally an integral part and a consequence of HE internationalization as a global trend (Coleman 2006; Hultgren 2014, Macaro at al. 2018). Russian researchers appear to be pragmatic and tend to recognize opportunities brought by English particularly in the domain of publications. The perception of Russian students and faculty about English as a language of education, research and job opportunities is also pushing HEIs towards EMI at the micro level which is clearly a bottomup movement manifested through academics learning English, obtaining international qualifications in English, thus becoming more competitive on the job market (Lanvers \& Hultgren 2018).

While the reasons behind EMI growth in higher education vary depending on the country, the general move towards EMI is global (Dearden 2015; Watcher \& Maiworm 2014; Hultgren 2018; Fenton-Smith, Humphries \& Wilkinshaw 2017), and Russia is not an exception. Unlike Chinese and Japanese HEIs which claim to expand EMI for altruistic motives such as to contribute to the improvement of the developing world by promoting high-level education or gaining access to cutting-edge knowledge (Galloway 2017), Russian HEIs' motives are far from altruistic: revenue-generation and raising their positions in rankings, through attracting a larger number of international students and faculty. Salmi in his research paper "Road to Academic Excellence" (2011) suggests the two factors which can facilitate short term growth at any university: firstly, by strengthening the university teaching staff through attracting the ex-patriots back, and, secondly, by introducing English as a medium of instruction (Frumin and Salmi, 2013).

Russian universities have recently been concentrated on increasing their positions in rankings. Therefore, Russian HEIs have been trying hard to expand the number of international students and faculty, the number of international research projects and collaborations, the number of courses and programs taught in English and the amount of English-language research published in high impact international journals. Another important reason is revenue generation. Therefore, Russian HEIs need to offer courses taught in English to encourage academic exchange and attract academic mobility students from all over the world in addition to offering bachelor and master programs taught in English to attract feepaying international students. Hence, the most powerful contextual factor driving the growth of EMI courses in Russian HEIs is its direct positive impact on raising their positions in world university rankings to make Russian higher education more competitive on the world education arena. Primarily due to this positive aspect - attracting a larger number of international students - Russian universities have been voluntarily expanding EMI.

The expansion of EMI at an institutional level is also being encouraged by university management policy makers and stakeholders. However, it must be mentioned that some strategic decisions at the university level appear to be leading to 'Englishization', but in 
fact, none of these decisions have anything to do with English, rather they promote English indirectly, like in some other European contexts (Saarinen and Nikula 2012). Likewise, the development of EMI in Russian HEIs may be considered a consequence of the internationalization and, simultaneously, a sign of a top-down approach at the national level.

Russia's student population may not appear very international compared to other European countries, such as UK, Germany and France, and the OECD 2020 report indicated that Russia is not on the list among the key players on the international educational landscape. In 2018, Russia hosted only 4\% of international foreign students (OECD. Stat). International student mobility has been expanding quite consistently in the past twenty years. In the Russian Federation, the share of foreign or international students increased from $3 \%$ in 2014 to $4 \%$ in 2018 . Meanwhile $1 \%$ of Russian tertiary students are enrolled abroad compared to $2 \%$ in total across OECD countries. Among students leaving the Russian Federation to study, the most popular destination is Germany (OECD Education at a Glance, 2020).

International student mobility may be affected by political stability, government relations or tensions between countries. Even obtaining student visas might be difficult for the third world countries. In addition, the economic factor may also negatively affect international student mobility and international student admissions as developing countries have an inadequate budget and insufficient resources. In 2017, Russia's share of international, or foreign students at a tertiary level of education, was $4 \%$ against the $6 \%$ OECD average which is quite impressive, on the one hand. On the other hand, if we consider Russia's share of international or foreign students by education level, we will see dramatic differences at three educational levels: Russia's share of international or foreign students was $5 \%$ for bachelor's or equivalent compared to the 4\% OECD average; $7 \%$ for master's or equivalent compared to an average of $13 \%$ for OECD which is twice as small; $4 \%$ for doctoral or equivalent compared to $22 \%$ for the OECD average which is 3 times as small.

For example, the Higher School of Economics University (HSE) in Moscow offered 17 English-language master's programs, with a total enrolment of 568 students. "HSE has a number of academic mobility programs, under which 360 foreign nationals came to the university in 2015 for a period of at least a month, the top sending countries being Germany, South Korea, USA, China and the UK. The most popular are one-semester programs, including English-based courses and intensive Russian language courses" (Nefedova 2017, 10)

The overall numbers of international students applying to Russian universities from the west are still quite low for numerous reasons: uncertainty in terms of what to expect and a lack of updated information, climatic conditions, and different culture, to name a few. Programs and courses taught in English should also be actively promoted among Russian students. More domestic students should be willing to switch to English as it will speed up their social and economic mobility and it will improve their job prospects making them more competitive on the global job market. Russian HEIs will benefit from a truly international classroom with a truly international cohort of students as an important part of internationalization. EMI education enhances English language and intercultural skills and the competencies of Russian students as well as faculty. An international classroom will make interaction in English meaningful. Moreover, it will resolve the complaint of international students who move to Russia hoping to join regular courses in English and to study alongside their Russian peers. As it stands now in most programs, foreign students who are not focused on the Russian language and Russian studies are placed in a 
tailor-made program, designed specifically for international students, and interact only with other foreigners. "Russian universities need to start offering more English taught programs. From the start, Russian students should be actively encouraged to enroll in them as well. The programs should be well promoted and visible on the latest digital media; foreign alumni should be used as ambassadors for the universities" (Verschoor 2017: 6). There is a considerable opportunity to increase the educational experience at Russian universities by having programs that encourage a truly 'international' classroom comprised of Russian and foreign students.

The scope and quality of English-taught programs in Russia seem to hold many potential international students back. Therefore, Russian universities should not only increase the quantity of English taught programs but also improve the quality of teaching in English. Considering the current situation and the ambitions of Russian universities, this paper discusses the currently available ways and strategies of improving the quality of university EMI teaching employed by Russian HEIs. To increase the quantity and the quality of EMI teaching Russian HEIs have been using the following strategies: international recruiting, long-term educational partnerships, and professional development programs.

\section{EMI FACUlTy DEVELOPMENT: STANDING ON THE SHOULDERS OF OTHERS}

In the process of implementing EMI at an institutional level, Russian academics and policy makers share some of the concerns widely debated in European higher education (Williams 2015, Shohamy 2012, Dearden and Macaro 2016). Research on Russian academics' attitudes and concerns indicated that the most widely shared concern of Russianspeaking EMI teachers is the insufficient, regarding content complexity, language level of English among the students admitted to EMI courses (Belyaeva \& Kuznetsova 2018). Other concerns include the required linguistic proficiency of the EMI teachers, their teaching competence in English, assessment validity of academic performance and the fundamental rational of EMI teaching in the absence of international students or including Russianspeaking international students.

The higher education EMI scenario all over the world is currently extremely diversified due to many reasons. Even in Russia the higher education landscape is quite heterogeneous due to a certain level of autonomy of Russian HEIs and independence of university faculties. However, many scholars and researchers have emphasized the need for EMI training for university teachers and lecturers in various contexts, where Englishtaught courses in universities are delivered by faculty, who are not English language teachers, to non-native English-speaking students.

EMI teacher training research has been aimed at establishing the ultimate goals for EMI teachers and, thus, discovering the most relevant content of EMI training. In general, EMI training focuses on two primary objectives: to improve English language competence and to adopt a wider range of teaching methodologies. Developing intercultural sensitivity and competence is oftentimes suggested as an additional goal.

The linguistic competence of EMI teachers is a widely shared concern, particularly in Southern and Eastern Europe and Asia. Unlike many outer circle countries (Kachru, 1992), where English has a better-established presence in the educational system often introduced at the primary level, Russia belongs to the expanding circle of countries where English has traditionally been a widely taught foreign language. English has always had a 
prominent role among other foreign languages taught at secondary schools, followed by German, French, Spanish and, recently, Chinese. (Russian State Exam statistics, 2020).

English is the compulsory foreign language at all levels of education in Russia and yet English language proficiency is ranked low. In the English Proficiency Index (EF EPI 2020), Russia scored 52 (low proficiency), placing it 38 out of the 80 countries in the world where people were tested. However, it ranked 24 out of 27 in Europe. English skills continue to lag in Russia like in other countries on the periphery of the European continent. Lagging far behind the Scandinavian countries, Germany, Austria and some other European countries with the highest level of English, Russia ranks on par with Italy, Spain, Albania and Turkey.

Despite English being one of the most widely taught foreign languages in Russia and despite its critical role in publications, technology, and Academia in the $21^{\text {st }}$ century, the linguistic competence in English is still inadequate among university teachers. The growth of EMI has caught the attention of content teachers and administrative authorities due to its impact on learning outcomes. Issues such as incorporating adequate teaching techniques, course materials, interdisciplinary collaboration, teacher training and assessment have been raised among Russian EMI practitioners. Regardless of the trend, controversial issues in conducting EMI in Russian universities have also resulted in debate and scepticism. Questions such as university content teachers' varying English proficiency levels as well as their readiness for EMI remains unanswered.

Another alarming issue that is still widely shared among Russian university teachers is the belief that to switch to EMI teaching they need to translate their lectures into English. To make them aware of the fact that translating their lecture into another language is not sufficient may be a serious challenge for an EMI training program as it requires working on attitudes. EMI requires more than merely translating content and delivering it. It involves teaching subject matter, supporting students learning this subject matter through English, often in classes with students from diverse lingua-cultural and educational backgrounds. Therefore, faculty may also need training in intercultural communication.

Well-designed faculty training is instrumental in determining the success of an EMI program. However, as Dearden (2015) points out, there are few pedagogical guidelines for effective EMI teaching and learning: there is little or no EMI content in initial teacher education (teacher preparation) program and continuing professional development (inservice) courses, which is concerning given the rapidly growing number of EMI programs worldwide. EMI presents a challenge of introducing faculty to the western style of higher education teaching with which they may not be familiar.

Few researchers have been investigating the content of EMI faculty development and providing recommendations to program designers of EMI training program. In Klassen's doctoral dissertation (2001), she recommends working on speech clarity, pronunciation, accent and vocabulary. According to Fortanet-Gomez (2010), EMI faculty should be trained in self-reflection on their pedagogic approach, metacognitive skills, assessment, lexis, and oral presentation. According to Dafoux Milne (2011), EMI lecturers should be trained to independently deal with language issues.

EMI local faculty needs should be examined. Current EMI needs analysis research provides valuable but limited insights for EMI training program design. For example, some Spanish teachers (Martín del Pozo, 2017) reveal that methodological concerns are of secondary importance after language up skilling. It has yet to be discovered what countryspecific needs analysis findings may indicate, however, they are quite informative and should feed into the process of EMI teacher training program design. 


\section{INCREASING EMI QUALITY TEACHING IN RUSSIAN HEIS THROUGH INTERNATIONAL RECRUITING}

To increase the number of courses taught in English, Russian HEIs need faculty who are both capable and willing to teach their disciplines in English. One obvious strategy is the so-called "international recruiting". To most western universities this is a non-existent notion as the academic market is open to everyone. However, in Russia and, possibly, in some Eastern-European countries and countries of the FSU (former Soviet Union), establishing the practice of "international recruiting" has been both a priority and a challenge. Russian Academia was isolated for a long time and during this period most international scholars worked in Russian universities through foreign agencies such as the British Council, Fulbright programs, personal connections, or other one-off arrangements, none of which were sustainable or large scale.

Although Russian HE has long been insular, the HE policies of the last decade have been seriously oriented at breaking this isolation and adopting the international standards. Recent HE initiatives such as Project 5 - 100 (established in 2013) and Export Education (approved in 2017) encouraged Russian HEIs to attract international talent. 21 Russian universities' (members of Project 5 - 100) KPIs include increasing the numbers of international students, courses and programs in English and international partnerships with foreign scholars and universities.

The Higher School of Economics University (HSE) was among the first Russian universities to successfully start recruiting international faculty back in 2007 using three main tracks: tenure-track positions, postdoctoral fellowships, and part-time positions for senior academics. "Currently there are 179 internationally recruited researchers working at HSE: 90 tenure-track faculty members, 18 faculty members holding tenured position, 47 postdocs and 24 senior researchers working part-time. However, the overall number of international academic staff at HSE is at least twice that, since many of them are invited to work at HSE international labs as lead researchers and some of them were recruited through standard procedures for non-tenure-track contracts." (Radaev 2019, 12). Another success story of international recruiting is the School of Advanced Studies (SAS) at the University of Tyumen (Siberia) which joined Project 5 - 100 in 2015. SAS "built its current permanent faculty body where $3 / 4$ of the faculty, representing 7 nationalities, hold a $\mathrm{PhD}$ from a university in the top-100 of THE or QS general university rankings" (Shcherbenok 2019, 15).

Since the leading Russian universities intend to become part of global Academia, they have been greatly involved in a worldwide search for the best scholars. HSE University and SAS at the Tyumen university have convincingly demonstrated success in attracting international faculty through academic mobility and recruitment strategies. However, it is explicitly stated that hiring faculty members and postdocs internationally is primarily aimed at enhancing research collaboration and building long lasting research teams, rather than teaching. Hence, the selection criteria favour research skills and experience over teaching competence and expertise. Similarly, international experts are often attracted by an opportunity to join exciting research projects, to open new research laboratories and to work in research-intensive HEIs. Perhaps, teaching at a Russian university would not be their top priority in seeking a job opportunity in Russia. And yet international experts who have been part of our academic community, even for a while, have made their contribution to teaching our students and exposing them to a different teaching style and different philosophy behind teaching. This by no means can be 
categorised as teacher training, but the exposure to different ways and traditions of western university teaching is paramount in providing Russian faculty with opportunities to learn from their foreign colleagues, even if informally through observations, sharing and professional exchange.

There is still much work to be done to establish a sustainable institution of international recruiting and to improve faculty retainment through standardising immigration procedures and residency visas. International faculty may be hesitant to stay long term and prefer employment elsewhere due to their lack of Russian language, family/spousal support, and the absence of an English-speaking academic community. Therefore, there is a need to continue the work on national and institutional policies as well as monetary and nonmonetary incentives to attract and retain international faculty. Many Russian universities unfortunately do not have a well-established reputation and history, nor do they have high positions in world rankings, and finally they may not have the resources required to attract foreign experts. Hence, most international faculty tend to concentrate either in the leading Russian HEIs with additional funding from the Russian government or in a handful of universities in Moscow and St Petersburg, being generally unwilling to move elsewhere across the country.

Recruiting international faculty as a strategy may offer certain valuable opportunities for further development of EMI in Russian HEIs, but at the same time it has serious risks and will likely remain in the position of a contributor to the EMI quality in Russian HEIs. This strategy does offer a "quick fix" solution with a foreign university professor stepping into the university classroom with fluent international English, English language subject specific terminology and professional jargon together with western approaches to university teaching and interacting with students. However attractive it may seem, increasing the number of international faculty is a short-term solution with certain risks and sustainability issues, but it does contribute to the quality of teaching and positively impacts students and local faculty.

\section{INCREASING EMI QUALITY TEACHING IN RUSSIAN HEIS THROUGH LONG-TERM PARTNERSHIPS}

In 1999 the Bologna Process established the European Higher Education Area (EHEA) and provided a framework for international higher education cooperation among universities from its 48 participating countries. It has played an important role in facilitating the dissemination of experience between universities and in establishing various practices of cooperation in international higher education. Double degree programs that allow students to obtain two degrees, one from a partner university in a different country, exemplify such practices. As a neighbouring country, Russia has been building the necessary trust for successful learning mobility, cross-border academic cooperation and the mutual recognition of qualifications and learning periods abroad completed at other universities outside Russia.

In 2008 multiple universities from Russia and other countries established the Network University of the Shanghai Cooperation Organization (SCO). Over the last few years, university cooperation between the BRICS countries has been expanding rapidly. With the BRICS Network University, BRICS University League and other similar educational forums, Russia is attempting to put itself at the center of a changing academic world, gaining access to the intellectual resources of the countries that together make up $40 \%$ of the world's population. 
The launch of the Bologna Process, with the aim of creating the EHEA, had a significant impact on the post-Soviet HE landscape. Eleven countries of the region joined the process and, consequently, have been reforming their HE systems to comply with the common principles. Subsequent Russian-led initiatives can be considered a "Eurasian" sub-region of higher education. These have been based on European principles, but take into account important features of post-Soviet countries. "Pursuing the same goal as the EU - to become one of the world leaders in the global education market - Russia sees the Bologna Process as a means of improving its competitiveness. At the same time, dissatisfied with its "periphery" position in the EHEA, Russia launched an Excellence Program and spearheaded alternative regional projects under its leadership" (Leskina 2019, 12). Regardless of the limited scope and funding, the SCO and Commonwealth of Independent States (CIS) network universities marked an important milestone by engaging universities in regional cooperation and supplementing intergovernmental processes. However, they include mainly elite universities based in capital cities, and thus, represent only a limited number of stakeholders. Russian universities have been attempting to take the lead in fostering cooperation with Eurasian Economic Union (EAEU) universities. For example, in 2016 Tomsk State University launched a joint Master's program with Kazakhstan and Kyrgyzstan on Eurasian integration to train students to work in EAEU institutions.

Finland, as one of Russia's closest European neighbors, and Russia have been enjoying fruitful cooperation including various internationalization activities between universities on both sides of the border. "Finland-Russia Higher Education Cooperation EDUneighbours investigated Finnish-Russian double degrees at the graduate level, found five Finnish universities implemented 18 master's programs announced with 23 Russian partners between 2014 and 2017 and selected seven double degrees with ten Russian partner universities from Northwest Russia and Moscow. [...] These activities led to the launch of double degrees under Finnish government funding for regional initiatives such as the Finnish-Russian Cross-Border University and the Finnish-Russian Student and Teacher Exchange" (Shenderova 2019, 21).

While traditional study abroad programs remain the predominant option for domestic students wishing to have an international experience, more Russian HEIs have been seeking ways to firmly embed international experience in their programs through launching jointdegree and double-degree programs. By a joint or double-degree program, we mean a collaborative study program (at the undergraduate and graduate level), all major elements of which have been agreed upon by the HEIs partners - curriculum, learning outcomes, learning methods, quality assurance, grading and credit transfer, admission procedures and staffing requirements, etc. Such programs are collaboratively managed, have a built-in mobility procedure, which is automatically recognised by partner institutions. The incentives for launching double-degree programs are obvious: advancing internationalization, increasing the academic mobility of students and faculty, raising institutions' international visibility and prestige. However, we would argue that this kind of cooperation between HEIs partners offers unique opportunities for stengthening teaching collaborations and developing innovative educational approaches through the joint work of international teaching teams and improved recruitment of international and local faculty. While implementing doubledegree programs Russian universities have the opportunity to gain a deeper understanding of the changes brought about by the Bologna process, which is still rather vaguely understood by the Russian academic community. 
Double-degree programs, as one well-explored format of long-term academic partnership between Russian and foreign HEIs, have significant potential for continuous professional development of the local faculty through their direct involvement in syllabus design, teaching methods and review of assessment systems, as well as improving quality assurance procedures. Such programs, based on the synergy of the unique experiences of each partner, allow teachers more freedom in expanding their repertiore of teaching methods and techniques, classroom practices and provide them with opportunities to develop specific competences relevant for lecturing and teaching in their subjects. Collaborative programs give local faculty excellent chances to gain multicultural experience, both in the academic and social sphere, to experience a variety of educational and cultural systems and traditions, to acquire a broader outlook. Furthermore, local faculty experience alternative and innovative educational and professional practices and obtain access to global educational and research resources and facilities that might be absent at their home universities. In establishing international collaborative programs, all the involved parties have to switch to English in both professional and social settings. Low English level proficiency among Russian university teachers has been seriously hindering and challenging the development and sustainability of most collaborative programs. Russian HEIs that aim at developing international programs and internationalizing their activities as a whole promote and encourage intensive language learning among staff and students, making English language one of the top priorities.

When planning and realizing joint and double degree programs special attention is paid to their compliance with the national procedures of each participating country. The Russian HE system remains quite centralized and governed by federally assigned standards which means that the curriculum and course content developed in cooperation with an international partner must fully comply with the Russian national educational standards and qualification framework, making the uneasy job of program setup even more difficult. Additional challenges are connected with planning academic activities on a program. Partners from different countries may implement different grading methods and scales to evaluate students. For example, in Russia more emphasis is put on oral examinations while in Europe and the US written tests are commonly administered. This is a serious challenge not only for students but for teachers, who need to adapt to different assessment methods and to design different assessment tools.

From our perspective, the benefits of having a strong international educational partnership outweigh the difficulties of its practical implementation, and universities should look into ways of overcoming such barriers. An undeniable advantage of establishing international partnerships between educational institutions and setting up joint and double-degree programs is the fact that such collaborations encourage the local faculty of Russian universities to explore diverse approaches and innovative teaching methods while also seeking new instruments to improving the overall quality of education and increase transparency and compatibility of curricula. The role of the local faculty in strengthening these long term partnerships is often underestimated. In order to make any joint or double degree program truly sustainable it should have a powerful local faculty professional development program which is aimed not only at increasing their English language proficiency, but also their teaching practices and underlying values and beliefs. A systemic deep-end approach to univeristy teacher development will probably lead to systemic changes in university teaching at an institutional level, however it may not be apparent immediately. 
In order to exemplify and illustrate the impact of an EMI teacher training for Russian faculty, conducted by an American HE instution, the partnership between Bard College, a liberal arts and sciences (LAS) college in upstate New York, and St Petersburg State University (SPSU) will be discussed. Bard's partner within SPSU is Smolny College which since 1996 has grown from a program within the Philology Faculty of SPSU to becoming Russia's first accredited Faculty of Liberal Arts and Sciences institution and a Faculty at SPSU. Since then several Russian universities of different calibre have expressed interest in developing liberal arts programs. Moreover, Bard College has set up new partnerships in the Kyrgyz Republic, Palestine, and Germany, and is launching new partnerships in Asia and South Africa. The liberal arts and sciences is far from being an easy system to adapt to, but Smolny College created a precedent of adapting LAS to the Russian educational environment. Bard College as a partner was context-sensitive, made an effort to familiarise itself with the local issues and showed sensitivity to what was locally essential at institutional level. Context-sensitive adaptation of a new educational approach and system should never be a one-way street. It should rather be a mutual process of exploring different educational traditions, reimagining old approaches and discovering opportunities for change.

The scope of this paper requires us to focus on the EMI teacher training program that has been offered to the Smolny faculty since the partnership started. Content-wise, this EMI teacher training program has a double focus: modern LAS pedagogy and the role of writing. English is a medium of instruction and never the focus of any teacher training event. The typical format of training events is a 5-day intensive seminar/webinar with a particular central theme. It is delivered in a group mode to facilitate faculty team building at an international level by the English-speaking Bard faculty. The key factors to the success of this EMI teacher training program is its relevance and being intellectuallystimulating and empowering (rather than equipping).

First, let us focus on the LAS pedagogy as it puts a serious emphasis on teaching and, thus, bringing the act of teaching into the focus of the trainees, raising their awareness of their own classroom practices and revisiting their teaching techniques. Smolny teachers are exposed to a very different approach in regard to the educational process and are led to gain a better understanding of a more interactive student-centered pedagogy. By participating in a series of seminars both in Smolny and at Bard, faculty are provided with methodology to expose their students to different points of view, to familiarize them with a variety of approaches and to probe issues, requiring them to read texts critically. "An interactive, student-centered pedagogy means that the classroom is not a one-way conveyor belt of knowledge from professor to student. Specifically, instruction does not simply consist of a teacher reading lectures to students, as is common throughout the world. The classroom is an environment in which students are encouraged to question assumptions and conclusions, analyze texts and derive their own interpretations, debate and role play, and to learn from one another" (Becker 2015, 41). In many ways this approach is similar to what has recently been called a "flipped classroom" when a significant amount of learning takes place outside of the classroom and prior to classes. Students are supposed to read significantly in order to prepare for a classroom discussion and/or to do their own research that is then reported on in class. Thus, students are empowered to offer informed insights and even to draw conclusions that differ from those of the teacher. For Russian university teachers this is quite a dramatic change in the role of a teacher and can be percieved as a serious threat to a teacher's authority in the traditional understanding. Within LAS pedagogy university 
teachers provide guidance, clarify issues, express their views and can be questioned and challenged, so they must be ready and willing to give up some authority. While for some Russian faculty this may be quite difficult at first, they may find it to be rewarding later as they observe that student-teacher relations acquire more of a collaborative nature. LAS pedagogy leaves room for different teaching styles and its pedagogic approaches, together with the degree of interactivity, vary according to discipline. Traditional lecturing can remain part of the repertoire of teaching techniques, but lecturing is of secondary importance compared to engaged discussion. Irrelevant of the discipline, there are elements of LAS pedagogy that must be present in the classroom as Becker has made apparent: "learning is interactive, students are encouraged to raise questions, challenge assumptions, and make their own discoveries, the teacher does not have a monopoly on knowledge, and a significant amount of learning takes place outside of the classroom" (Becker 2015, 42).

Since the LAS system has been institutionalised by Smolny College and the LAS key principles have been adopted, the local faculty faced the following requirements: to teach some of their courses in English (to provide students with an opportunity to study through English while also becoming prepared for academic exchange opportunities), to teach interactively (the size of the groups was reduced and limited to 15 students to allow for interaction), to develop a student-centered syllabus in English for their courses (a syllabus has to be given to students before the course starts); to review the continuous assessment procedures and to develop written exam questions in English (continuous assessment is no less important than the final exam); to grade students' papers in English and to provide feedback through which learning occurs. The EMI teacher training program was developed to assist local faculty in the above mentioned areas through tailor-made EMI seminars focused on all those aspects of teaching. Needless to say, the motivation of the local faculty to apply and participate in such relevant seminars was quite high and so was their effectiveness. Given that many among the local faculty had been accustomed to traditional didactic approaches, many local faculty members attended EMI teacher training seminars more than once until they became reasonably comfortable in LAS pedagogical practices and, finally, ready to meet its demands. The goals of the EMI seminars are multifaceted: proficiency in LAS pedagogy, linguistic competence as a result of the seminars being conducted in English, and confidence building. By experiencing firsthand pedagogical approaches, teachers increase their own self-esteem and confidence which are likely to be reflected in the classroom.

Another important focus of the Smolny College Russian faculty EMI teacher training is the methodology termed 'writing to learn' as writing is used to enhance the learning process for students. Back in the early 80-s, Bard College President Leon Botstein created the Language and Thinking Program with a particular focus on writing as an exploratory process to develop critical thinking. Later this program grew into the Bard College Institute for Writing and Thinking (IWT) which developed a series of workshops and seminars offered to Bard's international partners - institutions that do not have the extensive experience of viewing the classroom as a site of student-centered, active and engaged learning for students. Many faculty members were accustomed to a didatic approach of teaching where students are passive recipients of information. IWT teacher trainers have been preparing the Smolny faculty to encourage their students to ask questions, entertain new ideas, and listen productively. For university teachers who themselves came from an educational system in which rote learning was the norm, more collaborative and participatory forms of learning transformed their ideas of their new role and responsiblities in the classroom and how they can apply these in their classrooms. 
Russian faculty get an opportunity to attend 2 or 3 teacher training events every academic year, in addition to the possibility of visiting Bard College for a two week seminar in the summer, and to deepen their undestanding of writing-based techniques and its applications in the classroom. Together teachers explore how to internalise these practices, making them an intergrative part of the courses they teach. Faculty members reimagine writing prompts, work with new readings and integrate collaborative learning into their classrooms and adapt them to their subjects and their teaching styles. Examples of seminars provided to Smolny faculty in the past include "Writing and Thinking", "Writing to Learn", "Inquiry into Essay", "Writing to Learn in the STEM Disciplines", "Thinking Historically through Writing" and "Creative Nonfiction". These workshops create opportuities for university teachers of all subjects to experience learning through writing across all academic fields, benefitting from the supportive dialogue with their colleagues. Professional discussions in English help local faculty become more proficient in English while enriching their classroom and pedagogic discourse. Many of the techniques demonstrated provide first-hand experience to faculty in an attempt to make them more comfortable in introducing similar techniques in their own classes, irrelevant of the language of instruction.

Together with the well-established faculty training seminars offered by the Institute of Writing and Thinking, Bard College has demonstrated its ability to come up with tailormade teacher development events whenever there is a need. For example, earlier this year a tailor-made program "Writing to Learn and Liberal Arts Language Classroom" was offered to the Smolny language teachers at Bard College (Annandale-on-Hudson, New York) and tailored specifically to their professional and institutional needs. We would argue that this long-term partnership between Bard College (USA) and Smolny College $(\mathrm{RF})$ is a success story in EMI teacher training. The Smolny statistics demonstrates that among the approximate 130 courses across 12 fields of study each semester for bachelor students, approximately 20-25 courses are taught in English. This is strong quantitative evidence to prove the described above approach to EMI teacher training as both productive and efficient. The combination of formal EMI teacher training events with international teaching projects, teacher exchanges, Bard-Smolny online and face-to-face staff meetings and confrerences, exchange visits and study trips together with informal staff gatherings and team-building events result in a systemic institutionalised sustainable change towards an institutional switch to English as a medium of instruction and collaboration. A systemic approach to faculty development as a human resource development strategy results in an impressive outcome of such a partnership growing both HEIs into effective agents of change in their educational systems. What makes this partnership unique is its clear focus on the teaching excellence and commitment to making local faculty training and development one of the top priorities. It is important to note that this is a clear example of how truly international teaching teams evolve and together overcome the division into "us and them". They develop into one international team sharing the same education values and visions as well as classroom practices. To conclude, the strategy of a long-term partnership when and if implemented with a clear focus on systemic faculty development is an effective strategy for increasing the quantity and quality of EMI teaching. 


\section{INCREASING EMI QUALITY TEACHING IN RUSSIAN HEIS THROUGH EXTERNAL TEACHER TRAINING}

In 2019 a small-scale online research was done by Belyaeva to determine what kind of EMI teacher training options were available all over the world. The three available options discovered through this research will be briefly discussed below.

An EMI teacher training course in an English-speaking country developed and delivered by English speaking qualified professionals was the first option. EMI teacher training courses were offered by 5 institutions in the UK (Regent's University of London, Department of Education University of Oxford and Oxford EMI training, University of York, Wimbledon School of English in London and University of Liverpool), 3 universities in Australia (The University of Queensland (Institute of Continuing and TESOL Education), University of Alberta (language school) and Monash University Language Centre) and 1 university in Canada (Dalhousie University, Halifax, Nova Scotia). EMI teacher training programs offer professional support to university teachers planning to teach their academic subjects in English and to universities intending to create their in-house EMI support center. All the EMI teacher training programs consist of two key components: English language competence and university teaching methods. The EMI teacher training program length was one or two weeks of intensive work. Most of these course providers offer two options: university teachers could attend their teacher training programs in those countries and join multinational groups of teachers from different countries or, alternatively, EMI teacher trainers can travel to their HEIs in their countries to work with homogeneous and monolingual groups. However, most EMI teacher trainers are native English language teachers who work in a language center (not university faculty). International certification is offered to all the training participants.

The second available option is an EMI teacher training course in non-Anglophone countries: Zurich University of Applied Sciences in Switzerland (SHAW School of Applied Linguistics), Institute of Career Development in Pakistan, the Education University of Hong Kong, the University of Venezia (in partnership with University of California) in Italy, University of Freiburg Language Centre in Germany, and the British Council in France (Teaching Academic Excellence). The Universities offer a wider range of EMI issues including EMI courses, EMI research, EMI quality assurance and management, EMI conferences, EMI reading lists and e-resources and EMI workshops. These are also short intensive training events led by non-native English-speaking experts and language teachers offering international certification. Teacher trainers are also ready to travel anywhere to deliver any of the training events and quite flexible about the time and length of the training events.

The third available option has already been mentioned above - it is arranging for the EMI teacher trainer to arrive in Russia to a particular HEI or, perhaps, to a Russian city where several HEIs can bring their faculties together for an EMI teacher training. Duration, content, and format of an EMI teacher training event can be negotiated, and the content can be customised. For example, the Tomsk Polytechnique University invited English-speaking trainers to lead an EMI teacher training intensive program for its faculty.

One more available EMI training option should be mentioned here - MOOCs offered on international online education platforms by international teaching qualifications providers. There are currently 2 similar EMI-focused MOOCs: "English as a Medium of Instruction for Academics" developed by the University of Southampton on the "Future 
Learn" platform and "English for Teaching Purposes" developed by the Open University of Barcelona on the "Coursera" platform. These MOOCs are available to EMI teachers all over the world including Russian-speaking EMI teachers wherever they teach their subject courses in English. One more online EMI teacher training course developed by the Cambridge University Assessment "Cambridge English Certificate in EMI Skills" is only offered to HEIs should they wish to train and certify their EMI teachers online.

The strategy of external EMI teacher training has its advantages (exposure to professional English, western teaching methods and techniques), however it does have a serious disadvantage of highly qualified teacher trainers lacking relevant EMI experience as well as an insufficient understanding of the local context of the higher education system, thus, weakening their chances to offer relevant and context-sensitive EMI teaching practices. Besides, this strategy has far more serious limitations: a short intensive training event will not ensure qualitative language improvement, a teacher trainer from outside will not be familiar with the local EMI context, the intensive mode of a relatively short training event will not provide the necessary and sufficient practice, and, hence, it has hardly been used by the Russian HEIs.

\section{INCREASING EMI QUALITY TEACHING IN RUSSIAN HEIS THROUGH IN-SERVICE TEACHER TRAINING}

To increase the number of EMI courses and programs Russian HEIs have been encouraging their local faculty to start teaching their disciplines in English. Among the first to be encouraged to switch to EMI teaching are foreign-educated English speaking Russian faculty members with foreign degrees. The results of the survey of the EMI teachers of SPSU identified only $12,5 \%$ of the surveyed 72 SPSU EMI teachers educated abroad and only 8,7\% were degree holders (Belyaeva and Kuznetsova 2018, 430). We can only assume that those $12.5 \%$ of the respondents who graduated from universities abroad had to meet those universities requirements and should have at least a B2 level of English. Foreign-educated Russian faculty with a foreign degree are still a minority, but they seem most secure and confident to step into EMI teaching without any professional support or scaffolding as they have hands-on experience of being educated outside Russia and exposed to the western approaches to teaching and assessment. If St Petersburg State University (SPBU), one of the oldest universities in Russia, has such statistics, it is unlikely that any other Russian HEIs will have larger numbers of foreign-educated local faculty with foreign degrees.

The same survey indicated that among the SPBU faculty there were $20,8 \%$ who had various international English language qualifications and certificates, such as TOEFL, IELTS or Cambridge ESOL, indicating that their level of English is sufficient for EMI teaching. It should be mentioned, however, that the survey did not ask the lecturers to indicate their score or the language level according to CEFR, thus, we cannot be certain how proficient they are. Nevertheless, it needs to be mentioned that there are 4 International Examinations Centers in St Petersburg, but this may not be the case for many other Russian cities and towns. As a result, similar numbers of local faculty with international English language qualifications are unlikely to be found in an average Russian HEI. We can conclude that the local faculty who are confident to start teaching their disciplines in English is clearly a minority while the majority of local faculty all over Russia clearly requires EMI teacher training to start teaching their disciplines in English. 
One more strategy to increase the EMI quality teaching in Russian HEIs is in-service EMI teacher training which is designed and delivered by the local experts. Recently Russian HEIs have been encouraging local experts to offer professional support to those in need. Consequently, Russian higher education has been moving towards empowering nonEnglish speaking domestic faculty to step out of their comfort zone and start teaching their disciplines in English. Russian HE institutions have not been providing clear policy statements on EMI and the current trend is developing in an evolutionary way. As the quality of the lectures and seminars that are taught in English varies, Russian HE institutions have been working on the professional development opportunities internally.

Many Russian HEIs have traditionally had English language courses for their faculty either through their human resources department or through university-based language centers. However, EMI teacher training programs are still very few in Russia: St Petersburg-based ITMO University launched in-service EMI training for their faculty and later made it available for university faculty from all over Russia. Chelyabinsk-based South Ural State University (SUSU) launched a teacher-training course for English Medium Instruction together with the first locally published EMI textbook "English for Researchers: English Medium Instruction" (Volchenkova, 2018). The English Language Teaching publishing industry is surprisingly lagging behind and has not shown sufficient interest to create training materials for EMI teachers all over the world.

To better understand in-service EMI teacher training courses in Russian institutions, the course developed within St Petersburg State University (SPSU) will be looked at in more detail. This 72 academic hour EMI teacher training course has become part of SPSU internally certified professional development program. It is an extensive program and is delivered through 90 minutes sessions twice a week, which makes language improvement feasible. The program is aimed at educating and training highly qualified university teachers, non-native speakers of English, who teach (or intend to teach) their subjects and disciplines in English and work with international cohorts of students. This course consists of the following 3 modules: English for higher education teaching and classroom discourse (45 academic hours); Methodology of university teaching through English (15 academic hours) and Intercultural competence for teaching international cohorts of students (12 academic hours). All the 27 course participants (12 SPSU teachers in 2018 and 15 SPSU teachers in 2019) had a B1+ and B2 CEFR level of English and they unanimously rated their English language proficiency needs higher than those in teaching methodology. Among the classroom language the trainees intended to develop, the following were identified as their top priorities: signposting language for lectures and presentations, language of instructions, language for interactive tasks, elicitation and questioning, language of definitions and explanations; language for positive and constructive feedback and describing visuals and illustrations. All the phonology work aimed at accent minimization was received with enthusiasm by all the course participants.

Despite the fact that all 27 university teachers represented a wide variety of subject fields (Journalism, Law, Forensic Linguistics, International Trade History, Earth Science, Geology, Geography, Slavonic Studies, Economics, Medical Psychology, Physics, Computational Linguistics, International Relations, Political Science, Literature, Philosophy of Science and Art), they unanimously identified the following teaching competencies as their priority needs: course outline and syllabus design, assessment techniques and criteria, interactive ways of teaching and leading seminars, establishing a positive and comfortable classroom environment and feedback to students. Even though all the course participants 
rated the language module higher than the teaching methodology one, they expressed interest in the course activities, tasks and techniques used and mentioned. Responses from participants in their evaluations made it clear that they would be integrating some of the course activities into their own teaching in the future.

The intercultural module turned out to be the least popular and was not a perceived need, so the academic hour balance was changed in favor of English language work. Intercultural sensitivity is essential to manage intercultural differences in a multicultural and multilanguage classroom, but it had to be limited in scope and classroom time.

According to the needs analysis questionnaire, EMI trainees were most interested in developing their speaking, listening and writing skills. Reading, as the best developed language skill, was not at all a priority. Most trainees (25 out of 27) claimed they needed English to use it in lecture and seminar modes and only 2 trainees needed English for one-to-one academic supervision. The end of the course evaluation indicated that all the trainees improved their language skills in classroom discourse (speaking was the best developed skill) and felt more confident to teach their courses in English. The most popular course assignments were the following: to deliver a fragment of a lecture in the subject matter, to create a glossary of the course key terminology, to present a course outline, to give written and oral feedback, to lead a group discussion and poster presentations. Many trainees' feedback also indicated that moving into an online setting helped them discover a variety of teaching techniques to be used on online platforms.

The SPBU EMI course, together with the SUSU and ITMO expertise (presented and discussed at various conferences), make a convincing case for the strategy of in-service EMI teacher training to be quite promising in raising the EMI teaching quality and standards. It can grow into an effective context-sensitive and tailor-made EMI faculty training and development if it is competently institutionalized, managed and evaluated on a regular basis. We would argue that with growing scope and qualification awarded, this strategy can potentially resolve the current shortage of EMI faculty and positively impact the quality of EMI teaching.

\section{COMPARATIVE ANALYSIS DisCUSSION}

The scrutinized institutional strategies employed by Russian HEIs vary in their effectiveness and efficiency, however, there is much evidence to suggest that all of them have their limitations and weaknesses. The summary of the simplified comparative analysis is provided in the Table 1. The major criteria for comparing the discussed strategies include sustainability, recognition and status, financial implications and costs, logistics and infrastructure and risks.

The overall potential of each strategy should not be underestimated; however, it must be admitted that most Russian HEIs have been encouraged to search for "quick fix" solutions to facilitate the process of internationalization of Russian HE as part of a bigger agenda of Russian HE exports promotion and improvement of university rankings. Russian HEIs in their attempts to internationalize and to become more competitive on the global education market demonstrate a variety of approaches in increasing the quantity and quality of EMI ranging from degree programs fully taught in a foreign language (mostly English) to a combination of EMI and non-EMI courses. 
Table 1 Comparative analysis of the institutional strategies

\begin{tabular}{|c|c|c|c|c|}
\hline \multirow{2}{*}{$\begin{array}{c}\text { Criteria } \\
\text { for } \\
\text { comparative } \\
\text { analysis }\end{array}$} & \multicolumn{4}{|c|}{ Strategies employed by Russian HEIs } \\
\hline & $\begin{array}{l}\text { International } \\
\text { recruiting }\end{array}$ & $\begin{array}{c}\text { Long-term } \\
\text { partnerships }\end{array}$ & $\begin{array}{c}\text { External faculty } \\
\text { development } \\
\text { (one-offs) }\end{array}$ & $\begin{array}{c}\text { Institutionalized } \\
\text { faculty } \\
\text { development }\end{array}$ \\
\hline Sustainability & Low & High & Low & High \\
\hline $\begin{array}{l}\text { Recognition } \\
\text { and } \\
\text { status }\end{array}$ & $\begin{array}{c}\text { Expert status } \\
\text { Institution status } \\
\text { (prestige) }\end{array}$ & $\begin{array}{l}\text { Institution } \\
\text { status } \\
\text { Certificates } \\
\text { recognized }\end{array}$ & $\begin{array}{l}\text { Expert status } \\
\text { Certificates not } \\
\text { recognized }\end{array}$ & $\begin{array}{l}\text { Institution status } \\
\text { Certificate } \\
\text { recognized }\end{array}$ \\
\hline $\begin{array}{c}\text { Financial } \\
\text { implications }\end{array}$ & High & High & High & Low \\
\hline $\begin{array}{l}\text { Logistics and } \\
\text { infrastructure }\end{array}$ & $\begin{array}{l}\text { Limitations at } \\
\text { national level } \\
\text { (quota control) }\end{array}$ & $\begin{array}{l}\text { Established, } \\
\text { with some } \\
\text { institution- } \\
\text { specific } \\
\text { limitations }\end{array}$ & $\begin{array}{c}\text { No } \\
\text { infrastructure, } \\
\text { typically } \\
\text { a one-off } \\
\text { arrangement }\end{array}$ & $\begin{array}{l}\text { Long-established } \\
\text { faculty } \\
\text { development } \\
\text { procedures }\end{array}$ \\
\hline Risks & $\begin{array}{l}\text { Political issues } \\
\text { Personal } \\
\text { circumstances }\end{array}$ & $\begin{array}{l}\text { Political issues } \\
\text { Partners' } \\
\text { reliability and } \\
\text { commitment }\end{array}$ & $\begin{array}{l}\text { Political issues } \\
\text { Experts } \\
\text { availability }\end{array}$ & No risks \\
\hline $\begin{array}{l}\text { Overall } \\
\text { potential }\end{array}$ & High & High & $\begin{array}{c}\text { Only if the } \\
\text { objectives are } \\
\text { feasible }\end{array}$ & High \\
\hline
\end{tabular}

Unfortunately, the issue of the quality of university disciplines taught in English has been getting insufficient attention among Russian educationalists and researchers, and the number of publications reporting EMI-related research or describing university practices in EMI implementation remains limited. In the few recently published articles which analyze the current state and prospects of development of English-language education programmes at Russian universities (Anureyev, 2017; Kurgansky, 2018), some problems have been identified and recommendations have been suggested. The issues and concerns shared by the local university lecturers who start teaching subject content through a foreign language typically include insufficient language-related training, an insufficient language level among the students and a lack of interactive techniques. The traditional lecture-and-test model is still dominant in most Russian universities and the growing opportunity to teach in a foreign language should be combined with the introduction of different pedagogic approaches and methods such as experiencial, discovery and collaborative learning to make university teaching more student-centered and student-oriented. This may require a different set of professional competencies and needs and clearly highlights the lack of a preservice training framework for university lecturers and teachers adapting to teahing in a foreign language or in English as the currently prevailing medium of instruction.

The currently employed strategies by Russian HEIs are limited to in-service faculty training and are being implemented at an institutional level by universities and work more or less efficiently depending on a number of context-sensitive factors. However, there is clearly a need for a research of the EMI phenomenon in the context of Russian 
HE in general and the identified problems and issues involving university teachers and students on a larger scale to ensure the convincing evidence of the research findings. Research-based evidence of the current practice can lay a foundation with an innovative pedagogic framework for pre-service teacher education and training which will breed a new generation of teaching cadre in Russia.

\section{CONCLUDING COMMENTS}

The central theme of this paper was the quantity and quality of EMI teaching in Russian HEIs and the strategies of improving EMI teaching in Russian HE. Among the strategies currently available to Russian HEIs, we considered international recruiting, long-term educational partnerships, and teacher training. International recruiting can be considered as a short-term measure fundamentally lacking sustainability and requiring substantial financial resources. EMI teacher training supported externally by foreign experts from outside is both short-term and costly. The two most promising and effective strategies for EMI training and professional development are long-term HEI to HEI partnerships and inservice locally designed and delivered teacher training extensive programs. In both cases the results may not be immediately apparent, but in the long run both strategies will bring about systemic positive change and can positively impact EMI teaching quality.

Currently there are no EMI policies in Russian HEIs, and linguistic competence is one obvious obstacle to EMI in Russia. In most Russian institutions EMI is an evolving practice with varying institutional support. Some Russian HEIs have goals regarding EMI and there may be an evolving EMI policy, however, due to the galloping internationalization of Russian HE many institutions lag behind in offering their faculty intensive language support. Depending on how important EMI becomes to an HEI, the linguistic competence in the language which is the medium of instruction will be shaping university faculty careers in future. We are hopeful that EMI teacher requirements are likely to change over time and that linguistic competence will become as important as subject expertise since EMI teacher excellence is a combination of the two.

A closer assessment of effectiveness of the discipline-appropriate and contextsensitive pedagogy and its connection to the expected learning outcomes is also essential to guarantee quality of the university courses taught in a foreign language. There is a need to develop a pedagogic and linguistic framework for professional practice would help promote excellence in teaching and learning in a foreign language in Russian HEIs.

\section{REFERENCES}

Anureyev, Sergei. 2017, November. Англоязычные программы экономических вузов: недочеты и перспективы [English taught programs in economics universities: drawbacks and perspectives]. Образование [Education], 242, 8-9. https://trv-science.ru/2017/11/ angloyazychnye-programmy-ekonomicheskix-vuzov/

Becker, Jonathan. 2015. Liberal Arts and Sciences Education: Responding to the Challenges of the XXIst Century. Voprosy obrazovaniya/Education Studies. Moscow. 2015. No 4: 33-61. 
Belyaeva, E., Kuznetsova, L. (2018). Implementing EMI at a Russian University: A study of content lecturers' perspectives. Journal of Teaching English for Specific and Academic Purposes, 6 (3), 325-439.

Dvoretsky, Dmitry, Dvoretsky, S, Dvoretskaya, E. 2013. Perspectives and Challenges of Developing Joint and Double-Degree Programs I Russian Higher Professional Education. Conference paper. September 2013.

Costa, F. 2015. English Medium Instruction (EMI) Teacher Training Courses in Europe, in Recognizioni. Rivista di lingue, letterature e culture modern, vol. 2., No 4, pp. 127-135

Coleman, James A. 2006. English-medium teaching in European Higher Education. Language Teaching, 39(1) pp. 1-14.

Dafouz Milne, E. 2011. English as a Medium of Instruction in Spanish Contexts, in Y. Ruiz de Zarobe (eds), Content and Foreign Language Integrated Learning, Bern, Peter Lan: 189-209.

Dearden, J. 2015. English as a Medium of Instruction - a Growing Phenomenon. www.teachingenglish.org.uk

Fenton-Smith, B. et al. (eds.), (2017). English Medium Instruction in higher education in

Asia-Pacific. Multilingual Education, 21. https://doi.org/10.1007/978-3-319-51976-0_3

Fortanet-Gomez, I. 2013. CLIL in Higher Education: Towards a Multilingual Language Policy. Clevedon: Multilingual Matters.

Gustafsson, M., Jacobs, C. (2013). Editorial: Student Learning and ICLHE - Frameworks and Contexts. Journal of Academic Writing, 3 (1), 1-12.

Hultgren, A. K. (2014). English language use at the internationalised universities of Northern Europe: Is there a correlation between Englishisation and world rank? Multilingua 33.3-4, 389-411.

Johnson, Karin F. C. 2019. The Internalization of Higher Education: Faculty and Postdoctoral Researcher Recruitment Initiatives in Russia. Higher Education in Russia and Beyond /N 2 (20)/Summer 2019: 15-16.

Kachru, B. B. 1992. The Other Tongue: English Across Cultures. Illinois: University of Illinois Press.

Khomyakov, Maxim. 2019. University Networks in the BRICS: New Approaches to Academic Partnership. Higher Education in Russia and Beyond /N 1(10)/Spring 2019: 10-11.

Klaassen, R. C. 2001. The International Diversity Curriculum: Challenges in EnglishMedium Engineering Education, Doctoral thesis, Delft, Technische Universiteit Delft.

Klaassen, r. c., de graaf, E. 2016. Facing Innovation: English Medium Instruction in a NonNative Context Delft University of Technology

Kurgansky, S. A. (2018). English-language education programmes at universities. Bulletin of Baikal State University, 28(4), 595-601.

Lanvers, U., Hultgren, A.K. (2018). The Englishization of European education: Concluding remarks. European Journal of Language Policy, 10(1), 147-152. https://www.muse.jhu. edu/article/690801. Accessed 22 August 2020.

Leskina, Natalia. 2019. Is a Eurasian Higher Education Area in the Making? Higher Education in Russia and Beyond /N 2 (20)/Spring 2019: 12-13.

Macaro, E., Akincioglu, M. \& Dearden, J. (2016). English-medium instruction in universities: A collaborative experiment in Turkey. Studies in English Language Teaching 4.1, 51.

Macaro, E., Curle, S., Pun, J., An, J., DEARDEN, J. (2018). A systematic review of English medium instruction in higher education. Language Teaching, 51, 1, 36-76. https://doi.org/10.1017/S0261444817000350 
Madhavan, DIVYA, McDonald, JULIE. 2014. English as Medium of Instruction (EMI): Philosophia and Politics. OECD Higher Education Program Webinar given at Ecole Centrale Paris, 16 June 2014.

Nefedova, Alisa. 2017. Why International Students Choose to Study at Higher School of Economics. Moscow. Higher Education in Russia and Beyond /N 2 (12)/Summer 2017: $10-12$.

OECD (2016). The internationalisation of doctoral and master's studies. Education Indicators in Focus (39). OECD Publishing. https://doi.org/10.1787/5jm2f77d5wkg-en

Peoples, Peg. 2015. Empowering Students through Language and Critical Thinking. Voprosy obrazovaniya/Education Studies. Moscow. 2015. No 4: 116-131.

Radaev, Vadim. 2019. The Evolution and Impact of International Recruitment at Higher School of Economics University. Higher Education in Russia and Beyond /N 2 (20)/Summer 2019: 11-13.

Angeles, Maria, del Pozo, Martin. 2017 Training Teachers for English Medium Instruction: Lessons from Research on Second Language Listening Comprehension Revista de Lingüística y Lenguas Aplicadas Vol. 12 año 2017, 55-63 EISSN 1886-6298 https://doi.org/10.4995/rlyla.2017.6986

Saarinen, Taina and Nikula, Tarja (2012): Implicit policy, invisible language: policies and practices of international degree programmes in Finnish higher education. In A. Doiz, D. Lasagabaster, J. M. Sierra (eds.) English-medium Instruction at Universities^ Global Challenges. Clevedon: Multilingual Matters.

Salmi, J. D. 2011. The Road to Academic Excellence: the making of world-class research universities. Washington

Salmi, J. D., Frumin, I.D. 2011. Как государства добиваются международной конкурентособности университетов: уроки для России [Excellence initiatives to establish world-class universities: Evaluation of recent experiences]. Educational Studies, $1,25-68$.

Schmidt-Untergerger, Barbara. 2018. The English-medium paragidm: a concepetualisation of English-medium teaching in higher education. International Journal of Bilingual Education and Bilingualism. Volume 21, issue 5, 527-539

Shcherbenok, Andrey. 2019. Hiring (Many) International Faculty in a Siberian University. Higher Education in Russia and Beyond /N 2 (20)/Summer 2019: 14-15.

Shenderova, Svetlana, Lanko, Dmitry. 2019. Building Higher Education Cooperation Across Regions: The Case of Finnish-Russian Double Degree Programs. Higher Education in Russia and Beyond /N 1 (19)/Spring 2019: 20-22.

Sholamy, E. 2012. A critical perspective on the use of English as a medium of instruction at Universities. In Doiz, A., Lasagabaster, D. \& Sierra, J. M. (eds.), English-medium instruction at universities: Global challenges. London: Longman, 196-213.

Wachter, B., and F. Maiworm, eds. 2014. English-taught Programmes in European Higher Education: The State of Play in 2014. Bonn: LemmensMedien GmbH

Verchoor, Jerke. 2017. Study in Russia, Study in English. Higher Education in Russia and Beyond /N 2 (12)/Summer 2017: 6-7.

Volchenkova, K, BRYAN, A, Semenova, Y. 2018. Journey Without Maps: Designing a Teacher-Training Course for English Medium Instruction. EDULEARN Proceedings. Pp. 1123-1134. DOI: 10.21125/edulearn.2018.0737 